\title{
César Martínez-Silva Del arte incendiario y neumático a las perforMANcenas
}

\author{
María L. González
}

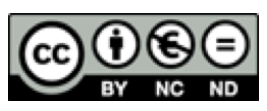

Esta obra está bajo una licencia Creative Commons

Reconocimiento-No comercial-Sin Obra Derivada 

Artículos

\title{
César Martínez-Silva Del arte incendiario y neumático a las perforMANcenas
}

\author{
María L. González. \\ Doctorado Interinstitucional en Arte y Cultura/Universidad Autónoma de Aguascalientes \\ Estancia posdoctoral. CONACYT \\ marialuisagonzalez.aguilera@gmail.com
}

Recibido: 26 de mayo de 2016 Aprobado: 27 de setiembre de 2016

\begin{abstract}
Resumen
Para César Martínez-Silva (Ciudad de México, 1962), la incorporación es un elemento pleno de fuerza metafórica. Al encontrar una equivalencia simbólica entre metabolismo cultural y metabolismo socioeconómico -y entre las producciones artísticas y cualquier creación humana que genera un ciclo de consumo -, el artista elabora el concepto de las perforMANcenas. Estas son performances conceptuales en las que el artista ofrece, para su consumo, esculturas comestibles en forma humana, las cuales se articulan, de forma conceptual, en la trayectoria del artista, en una sucesión que va del arte incendiario realizado con pólvora, al arte neumático realizado con aire; de sucesos significativos de su infancia que atraviesan y marcan su vida personal, a sucesos políticos relacionados con la incorporación que trascienden el plano individual para marcar la vida social y económica. El propósito de este artículo consiste en mostrar la génesis de este concepto, orientándome, para ello, con el método que A. C. Danto (2009) sigue para el abordaje de las producciones artísticas contemporáneas. Dicho método consta de tres preguntas fundamentales, las cuales se mencionan a continuación: ¿quién hace la obra?, ¿qué hace el artista? y, finalmente, ¿cómo hace la obra el artista? Se inicia, por tanto, con el manifiesto del artista; de forma posterior, se describe su trayectoria en la que se realiza énfasis en sus principales referentes y principios estéticos y algunas de sus producciones.En última instancia, se otorga énfasis a la configuración de las perforMANcenas y su propuesta estética.
\end{abstract}

Palabras clave: César Martínez-Silva, perforMANcenas, incorporación, arte explosivo, arte neumático, A. C. Danto. 


\title{
Artículos
}

\begin{abstract}
For César Martínez-Silva (Mexico City, 1926), the incorporation is an element full of metaphorical force. To find a symbolic equivalence between cultural metabolism and socioeconomic and between artistic production and any human creation that generates a consume cycle, the artist elaborates the concept of perforMANcenas. That is conceptual performance in which the artist offers for consume, human shape edible sculptures. These articulate conceptually on the artist's path, in succession that goes from incendiary art, made with powder, to pneumatic art made with air; from significant events of his childhood, that crossing and mark his personal life, to political events related whit incorporation that transcend the individual level to mark the social and economic life. The proposal of this article is show the genesis of this concept, orienting myself for this whit the method that A. C. Danto (2009) follow to approach contemporary artistic productions. It consists of three fundamental questions: Who made the work? What the artist made? and How the artist made the work? Beginning, for that, whit artist manifest, continued whit his career in which I emphasize its key players and his aesthetic principles and some of his productions, and finally I focus on the configuration of PerforMANcenas and his aesthetic proposal.
\end{abstract}

Keywords: César Martinez-Silva, perforMANcenas, incorporation, explosive art, art fire, A. C. Danto. 


\section{Semblanza}

\section{El arte es de quien lo trabaja ${ }^{1}$}

Depositar la credibilidad en uno mismo. Esa es la milagrosa aparición del arte.

César Martínez. ${ }^{2}$

Decir quién es César Martínez es un reto. Como artista plural, con una trayectoria de más de 20 años, y una muy variada producción, resulta difícil catalogarlo o resumir en pocos renglones su enorme personalidad, considerando que le resultaría incongruente consigo mismo encasillarse de maneras fijas, ya que este se define a sí mismo como un "artista indisciplinado"3 ; de tal forma, se intenta, sin embargo, definir su perfil, en aras de transmitir la visión que me he forjado de él a través de conocerlo, conocer su obra, conocer lo que se ha escrito sobre él, lo que él ha escrito sobre sí mismo y lo que piensa de los temas del arte, todo ello con miras a construir una imagen unificada que constituya nuestro punto de partida para el abordaje de las PerforMANcenas, su creación original.

Como arte efímero, se puede participar en sus presentaciones solo de manera presencial, u observando, después, las documentaciones fotográficas y fílmicas de estas. He experimentado dichas formas y ambas proveen una intensa experiencia.
Conocí a César Martínez el año de 2009, siguiendo la ruta de artistas mexicanos contemporáneos que trabajaran con el tema del cuerpo. Mi investigación de doctorado era sobre arte corporal (El artista corporal como sublimador de la subjetividad posmoderna, 2013). Me interesaban, de manera particular, aquellos artistas que mostraran con su obra la mutación subjetiva que acontece en nuestra época y, de forma más particular, aquellos que emplearan en sus estrategias estéticas, modalidades que a su vez mostraran el paso de la representación del cuerpo, a la presentación de este.

Enseguida, muestro algunos datos biográficos relevantes del artista. César Martínez-Silva nació en Ciudad de México, en 1962. Hizo su formación en la Academia de Artes La Esmeralda. El arte experimental ha sido su factura. Ha explorado diversas modalidades expresivas entre las que se encuentran la escultura expandida, la fotografía, la escultura en pequeños formatos, el performance, el intervencionismo y el accionismo. Es autor de obras efímeras, procesuales, collages, ensamblajes, imágenes alteradas, electrografías, relieves postescultóricos, instalaciones y performances (Blas-Galindo, 2015).

\footnotetext{
${ }^{1}$ Título con el que el artista expone sus puntos de vista acerca del arte y los artistas. Recuperado de la biografía de Martínez-Silva en http://martinezsilva.com/articulos/La\%20Obra\%20De\%20Arte.pdf

${ }^{2}$ Tomado del archivo del artista. Publicado en el catálogo El final del Eclipse. El arte de Latinoamérica en la transición del siglo XXI. Fundación telefónica.

${ }^{3}$ Así se define en su autobiografía. Recuperado de http://martinezsilva.com/index.php?/artista-indisci/biografia/
} 


\section{Artículos}

Martínez-Silva se distingue por ser un "artivista"4 interesado en incidir en la vida sociopolítica de nuestro tiempo. Ha sido becario del FONCA (Fondo Nacional para la Cultura y las Artes) y actualmente pertenece al SNC (Sistema Nacional de Creadores). Además, es catedrático en la Universidad Autónoma Metropolitana, unidad Azcapotzalco, en el área de Artes visuales, principalmente en las materias de Semiótica e Historia del arte. Este participa en una gran red de artistas y curadores ocupados en desarrollar y presentar, en diversos foros, el performance político.

Los temas centrales de César Martínez-Silva son el cuerpo y sus vicisitudes existenciales: el tiempo, la muerte, el proceso de creación de la obra, la función del arte, su consumo, así como los cambios sociopolíticos y las posibilidades transformadoras del arte como medio de conocimiento. Para este artista el arte no es sino compartido y coproducido con el público participante, el cual considera que el sentido de la obra emerge en ese encuentro. Inmerso en la estética contemporánea del instante, juega con el tiempo, creando un arte efímero que, sin embargo, se integra a la dinámica de la vida, generando una experiencia estética transformativa.

El metabolismo es una de sus metáforas preferidas para comunicar, con ello, que el arte se incorpora y se metaboliza, cual si fuera un alimento o proteína simbólica: se percibe, se incorpora, se asimila y se transforma. Generar nuevas formas para mejorar la vida social está dentro de sus propósitos. Este considera que al artista le es posible articular una respuesta estética frente a lo que acontece en su tiempo, puesto que ya tiene una percepción estética. Lo peculiar del artista es, según Martínez-Silva, que este articula esa percepción en una propuesta artística, cercana a lo que ya Nietzsche planteaba en La voluntad de poderío como arte (Nietzsche citado en Vattimo, 2007), texto en el que desplegó, en concreto, la función de preludio, de anticipación y de modelo que tienen el arte y los artistas en los fenómenos del mundo.

Martínez-Silva formula este propósito como una "trans-forma-(ac)ción". Dice en lo que es posible considerar como su manifiesto:

$\mathrm{El}$ arte y los artistas jugamos un papel no solamente reconciliador con la vida [...] también podemos crear una interactividad más efectiva en lo social y en lo político. Los artistas podemos ser consejeros civiles y del Estado, [...] profesionalizando nuestro trabajo para incidir en las decisiones políticas y civiles, proponiendo un nuevo arte de hacer el arte, creando más espacios públicos nuevos para las artes, para su distribución y consumo. (Martínez-Silva, s.f.)

Martínez-Silva posee ya "marcas autorales" que permiten distinguir sus obras con respecto a las de otros artistas. Esto debido a que, además de hacer un arte plural, ha desarrollado constantes estilísticas que le confieren solidez y la formación de un lenguaje individual (Blas-Galindo, 1988). Este se

${ }^{4}$ Término con el que el artista se autonombra. Reúne sus dos intereses: el arte y el activismo político. 
distingue, entonces, por un arte rebelde y subversivo con una extraordinaria fuerza expresiva. Una constante presente en casi toda la obra es la dislocación simbólica, procedimiento con el que este artista, a través del empleo de metáforas del cuerpo y el canibalismo, intervine la vida sociopolítica (Arozqueta, 2006).

Martínez Silva se inscribe y adhiere a la tradición vanguardista que en la década de los ochenta, en México, se manifestó con movimientos grupales de arte experimental y creación de espacios alternativos tales como La Quiñonera y La Panadería, cuyo propósito central ha sido cambiar y revitalizar el diálogo entre el arte y la comunidad. En su manifiesto, el artista escribe:

La intención es, sembrar en la cima, una actitud, un encuentro, otro árbol adentro, una acción que repercuta en el futuro del espectador, no sólo reducida a la percepción visual. (es) como una "misión" a la hora de crear y producir. (Martínez-Silva, s.f.)

La máxima vanguardista que vincula arte y vida articula la obra de Martínez. En toda su trayectoria artística entrelaza elementos de la vida cotidiana social y política con el compromiso de transformar. $\mathrm{Al}$ respecto escribe: "Así como en la vida, el arte se hace y rehace a cada instante, se redefine en la cotidianidad, en la continuidad de la rutina inestable. (...) El arte se ha vuelto pues, una experiencia. O mejor dicho, una expeciencia" (Fundación telefónica, El final del Eclipse. El arte de Latinoamérica en la transición al siglo XXI, s.f.).
La identidad del artista es también posible conocerla a través de lo que este crea. En el siguiente apartado se procederá a mostrar parte de su obra.

\section{Trayectoria artística}

El arte se inserta en una perspectiva, como una pieza de filosofía leída en el momento correcto (Danto, Después del fin del Arte. El arte contemporáneo y el linde de la historia, 2009).

Como apuntamos en lo que antecede, la obra de César Martínez-Silva es muy amplia. Para los fines del presente trabajo, se hará énfasis, de forma particular, en dos grupos de obras emblemáticas que se forjaron a la par que las perfor $M A N$ cenas, y que, a mi juicio, representan en buena medida al artista. Estos grupos de obras son las denominadas: Artentados y Sucesos escultóricos.

\section{Los inicios}

Martínez-Silva se inició formalmente en las artes visuales, en la época en que aún inspiraba el expresionismo abstracto. Pollock fue uno de sus motivos de inspiración inicial por significar un arte vanguardista, innovador, en cierta manera rebelde y en ruptura con lo establecido, pero, sobre todo, por contener cierto germen de performance, vía que después tomaría con absoluta preferencia.

Pollock metía el cuerpo en el lienzo, como buscando unidad y continuidad entre el autor y la obra. Me mostró que la pintura, 


\section{Artículos}

aunque revolucionaria en su técnica es limitada para expresar las vicisitudes existenciales y políticas que nos ocupan (M.L. González, comunicación personal, 2015)

En su ejercicio como artista visual, dibujando y experimentando con papel y lienzo o con la fotografía, comienza a operarse una transición en la que Martínez-Silva va transitando del expresionismo al accionismo y se van gestando, con ello, las condiciones artístico-estéticas de emergencia del concepto de las perfor $M A N$ cenas. Al respecto, el artista enuncia:

La pintura y el dibujo son medios limitados para la comunicación. Yo quería generar un arte vivo, interactivo. Entonces comencé a relacionarme con artistas que empleaban su cuerpo como objeto artístico y, más particularmente, con los artistas que en nuestro país comenzaron a desarrollarse en el performance, entre ellos, Maris Bustamante y Guillermo Gomez-Peña los cuales hacían acciones clásicas -como ellos las llamaban- y entré a un mundo donde las posibilidades eran muchas y me adherí a la causa... yo, cuando era dibujante sentía que estaba comunicando una mínima parte. (M.L. González, comunicación personal, 2015)

Bourreau (1990) plantea que el arte contemporáneo se centra, de forma fundamental, en lograr la forma. Aunque algunos críticos como Blas-Galindo consideran a Martínez-Silva dentro del arte procesual, dicho autor se reconoce dedicado e interesado en crear nuevas formas. Al respecto dice: "La creatividad es una búsqueda inalcanzable, es algo que no tiene límites y es exigente en la medida que te permite averiguar cosas que te has planteado. La imaginación se apodera de ti en una especie de aura" (M.L. González, comunicación personal, 2015).

Cercano a Maris Bustamante y Rubén Valencia, reconocidos artistas del performance inicial en México, Martínez-Silva participó en sus inicios como asistente y performer con estos artistas en sus presentaciones denominadas Pornochou y Teatro de Objetos; así, el performance se le presentó como un medio pleno de posibilidades expresivas. En este sentido, el artista comenta: "El performance me gustó porque era algo más integral, permitía amalgamar fuerzas de comunicación que no eran gráficas exclusivamente" (M.L. González, comunicación personal, 2015).

Con Maris Bustamante, su maestra en Teoría política en la Universidad Autónoma Metropolitana -cuyas clases parecían un auténtico performance, según el autor-, Martínez encontró una vinculación con su historia y su búsqueda personal, con lo cual afirma: "[En] su manera de dar clases vi un recurso muy ingenioso que se vinculaba con la actitud de mi padre, que era como un performero nato, muy simpático, astuto e imaginativo [que] siempre me enseñó con la acción" (M.L. González, comunicación personal, 2015).

De forma posterior, con su tesis doctoral, se dio a la tarea de precisar la diferencia entre el activismo político y el arte-acción político. Dicha tesis titulada Cuerpo, política y subjetividad. El Performance y sus prácticas 


\section{Figura 1}

Serie Explosiciones. "El espesor del presente" (1990). Dinamita y nitroglicerina sobre acero inoxidable, $120 \times 80 \mathrm{~cm}$, Nortwood, New Hampshire, USA.

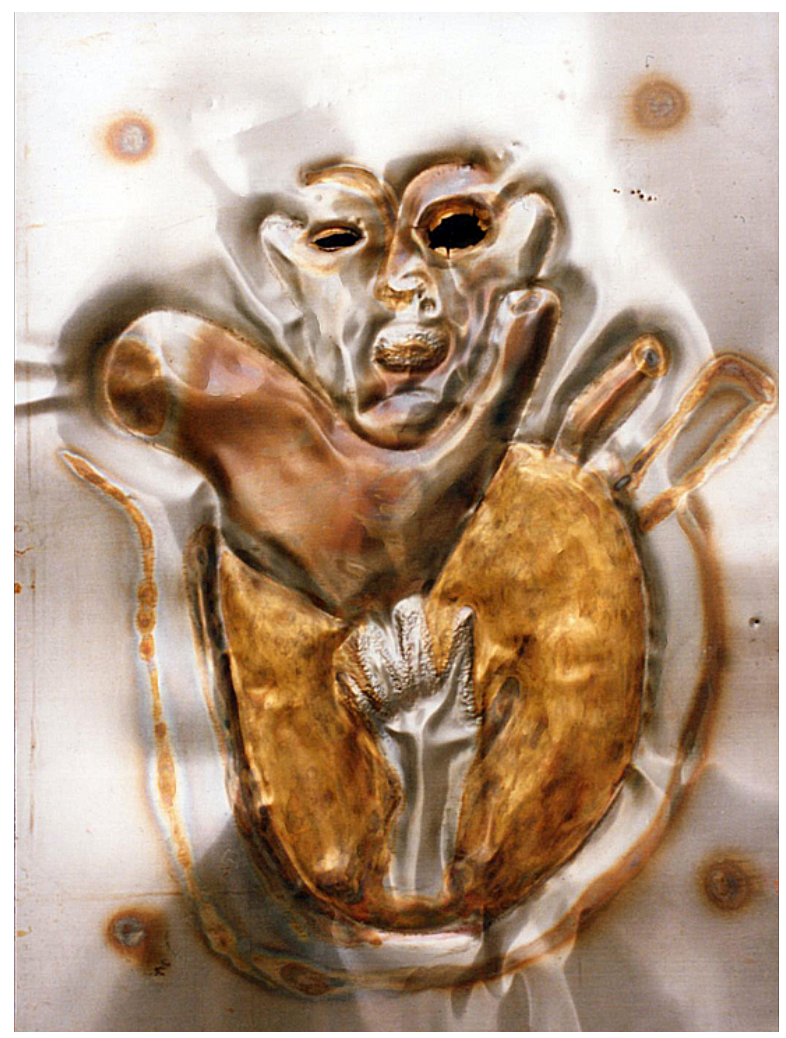

Fuente: César Martínez-Silva.

antagónicas $(2009)^{5}$, muestra que los movimientos civiles recurren al performance como una forma de vehiculizar su protesta, y que los artistas tienen un interés artístico, vivencial y existencialista. Los activistas pueden ser políticamente más auténticos porque no buscan un reconocimiento estético, sino social y político. De acuerdo con el autor, mientras que las acciones de los artistas -cuyo propósito es político- son registradas en un catálogo, estos obtienen remuneración y hay un crítico de arte que comenta la acción; la acción de un activista político puede, de forma eventual, tener reconocimiento en la prensa. Lo común entre ambos radica en que emplean formas con una enorme fuerza expresiva que crea un gran impacto emotivo y reacción. Cabe destacar que iniciarse en el performance le otorgó la experiencia de la expresión integral; no agotó sus inquietudes experimentales, expresivas y políticas. Explorar posibilidades artísticas con explosivos fue también su búsqueda, la cual toma forma en lo que denominó Art-tentados, práctica artística que se describe a continuación.

\section{Art-entados: Explotartes y Explosiciones}

Hay que ser una especie de Prometeo, dar el fuego al otro.

César Martínez-Silva (s.f.).

Si algo distingue a César Martínez-Silva es el gusto por la experimentación extrema, no solo en los medios empleados para la creación, sino también en las formas producidas y la relación con el museo y el público. Inspirado por el arte de acción de la década de los ochenta,

${ }^{5}$ Sobresaliente Cum laude, por parte de la UCLM (Universidad de Castilla La Mancha), campus Cuenca, España. 


\section{Artículos}

este concibe obras extramuros para ocupar espacios públicos o íntimos como patios o azoteas de amigos o galerías independientes.

Dinamita y pólvora fueron los medios empleados para realizar un arte incendiario, inspirado en Kandisky y su concepto de "energía interior", cuya idea central era el trabajo con la metáfora del fuego y el mito de Prometeo. Su propuesta conformó dos series a las que denominó Explotarte ${ }^{6}$ y Explosiciones ${ }^{7}$. Martínez-Silva se propuso en estas obras como un artista que "roba el fuego" para darlo, haciendo un símil del héroe mitológico que otorga el fuego como sabiduría para conservar la vida; en este sentido, el artista afirma: " [...] hay que ser una especie de Prometeo, dar el fuego al otro para que también se haga conciencia de que somos cuerpo, y de que hay una biopolítica ${ }^{8}$ que controla la vida" (M. L. González, comunicación personal, 2015).

En la serie Explotarte ${ }^{9}$, las formas creadas fueron esculturas incendiarias que, al explotar, develaban su figura y regalaban su olor. La intención consistió en generar un arte que explotase los sentidos y los activara vitalmente. José Jiménez, a propósito del arte

\section{Figura 2}

Serie Explotarte. "Lightining border" (1989). Mural efímero realizado con pólvora y fuego, Parque México.

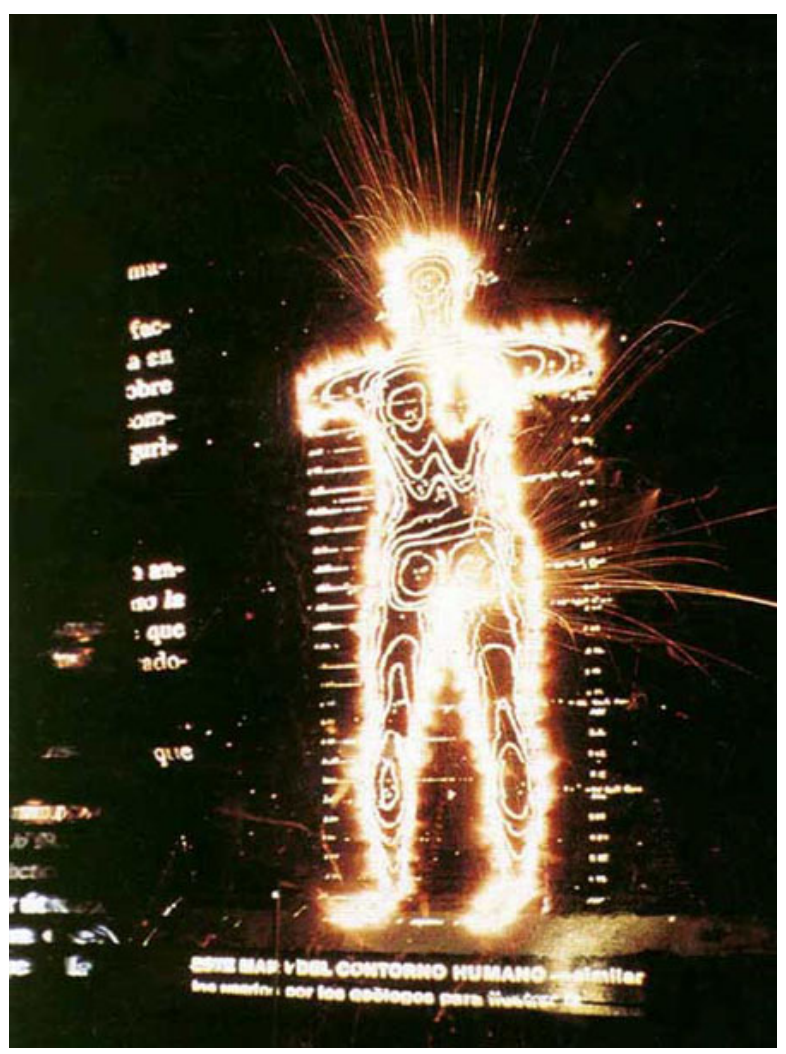

Fuente: César Martínez-Silva.

\footnotetext{
${ }^{6}$ Estas obras pueden consultarse en la página del autor Martínez-Silva, en el enlace http://martinezsilva. com/index.php?/artentados/explosiciones/

${ }^{7}$ Estas obras pueden consultarse en la página del autor Martínez-Silva, en el enlace http://martinezsilva. com/index.php?/artentados/explosiciones/

${ }^{8}$ M. Foucault con su Historia de la sexualidad ha sido uno de los autores de referencia del autor. El biopoder y la biopolítica son considerados por este para articular su obra y forman parte del desarrollo conceptual de las perforMANcenas, en las que tematiza el uso de los cuerpos y su territorialización.

${ }^{9}$ Serie realizada con pólvora, pigmentos y carbón vegetal que fueron detonados en presencia del público.
} 
Artículos

Figura 3

Serie Explotarte. (1987). Escultura efímera realizada con fuegos Art-ficiales, Tenochtitlán City, SOHOndesa Village.

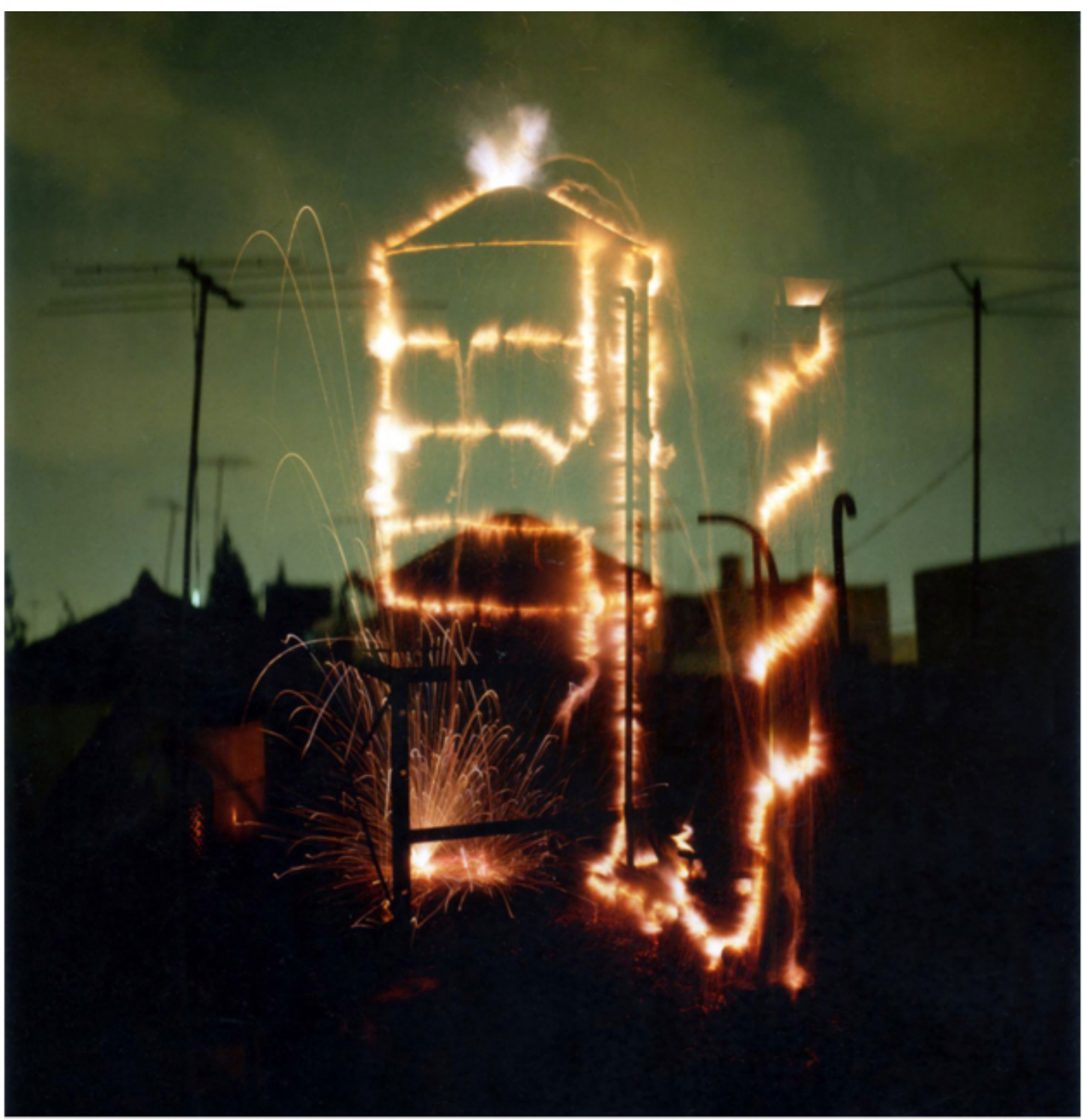

Ensayo de ARTEntado

Escultura efimera realizada con fuegos Art-ficiales

Tenochtitlán City, Down Town, SOHOndesa Village,1987

Fuente: César Martínez-Silva.

ESCENA.Revista de las artes, 2016, Volumen 76, Número 1, págs.27-58 ISSN 1409-2522 
Artículos

\section{Figura 4}

Serie Explotarte."El manantial como fuego" (1987). Escultura efímera realizada con fuegos Art-ficiales, Tenochtitlán City, SOHOndesa Village.

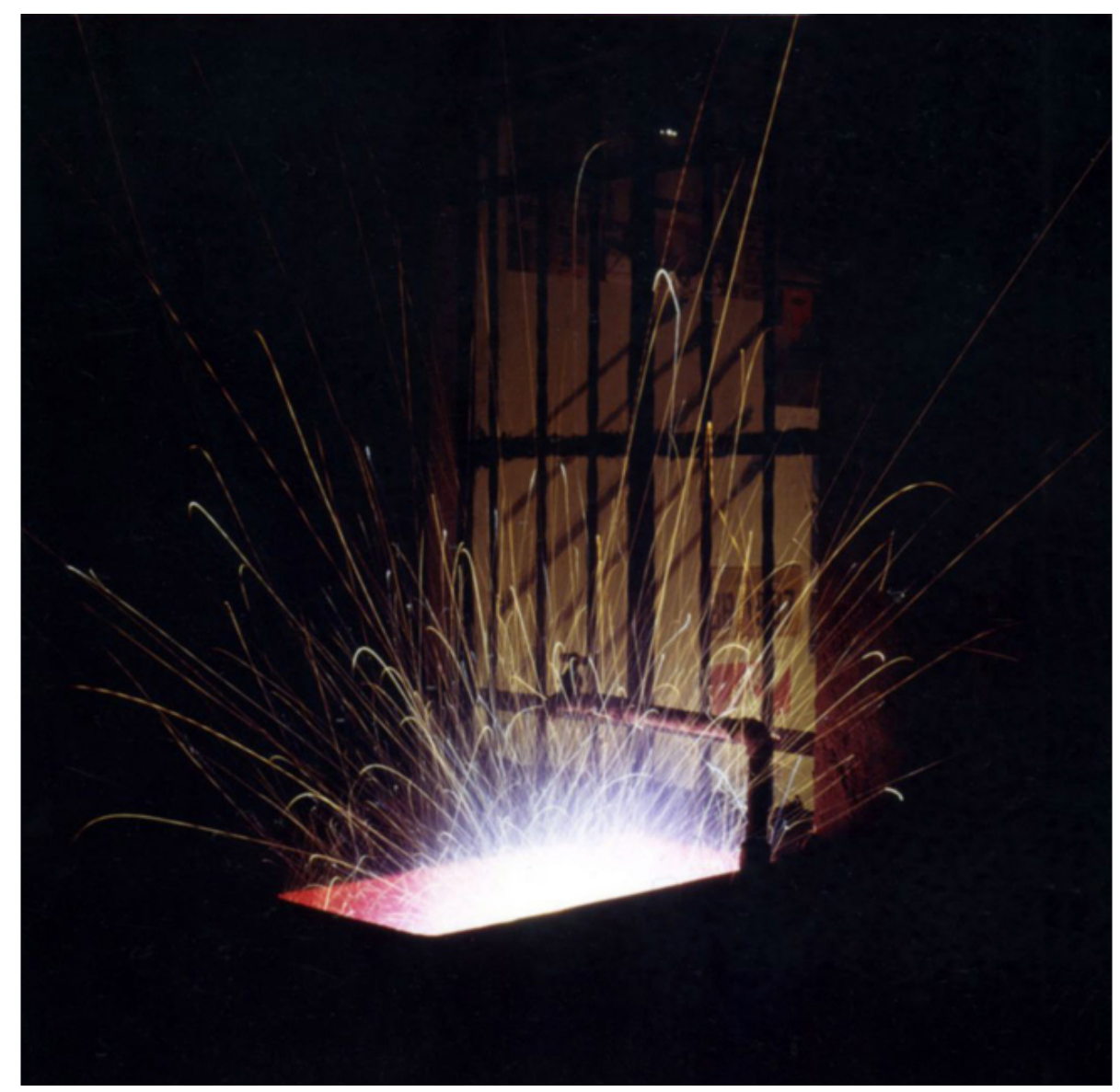

Fuente: César Martínez-Silva.

incendiario de Martínez-Silva, comenta: "Así, el carácter destructor del explosivo se convierte en llama de luz, de forma muy similar a lo que se expresa en el poema de Octavio Paz son llamas los ojos y son llamas lo que miran" (Paz citado en Martínez-Silva, 2015).
Martínez expresa en esta propuesta que “[...] la obra no era 'expuesta', el público era el que se exponía a un ARTEntado. El público detonaba las piezas con la ayuda de una cerilla, era testigo de su desarrollo, co-creador de la obra". La estética relacional iniciada en las vanguardias y retomada 
ampliamente en el arte de los ochenta, nominada formalmente en los noventa, por N. Bourriaud, es aquí patente.

En plena acción y ejerciendo un arte experimental, Martínez-Silva crea la siguiente serie denominada Explosiciones en las que el tema era el corazón y su sinrazón. La técnica varía hacia el dibujo sobre placa de acero a la que se le aplica el explosivo. Al respecto, el artista nos dice:

Me di cuenta que podía dibujar con pólvora, disparar cosas. En una performance me dedicaba a explotar, hacía unas cápsulas con pigmentos y pólvora que, al detonar, generaban color, y el público lo detonaba. Rompía con la pasividad. Convertía a la audiencia en un público creativo, porque ellos eran los que detonaban. Eso implicó romper mitos, la barrera multisensorial, porque se olía, se veía y se sentía. También implicó abrir brecha y buscar nuevos foros, rompiendo también estructuras burocráticas. (M. L. González, comunicación personal, 2015)

Para el artista estas acciones no significaban sólo romper o sacudir la psique del espectador, también se dirigían a generar otras maneras de hacer el arte, así como crear y conquistar nuevos foros y espacios.

Desarrollar el concepto de las esculturas explosivas tuvo cierta complicación debido a que, generalmente, la dinamita es asociada a un concepto bélico. De acuerdo con Martínez-Silva, tuvo que tramitar permisos oficiales para emplearla; no obstante, en el año

\section{Figura 5}

Serie Explosiciones. "¡Viva la muerte!” (s.f.). Dinamita y nitroglicerina sobre acero inoxidable, $70 \times 50 \mathrm{~cm}$

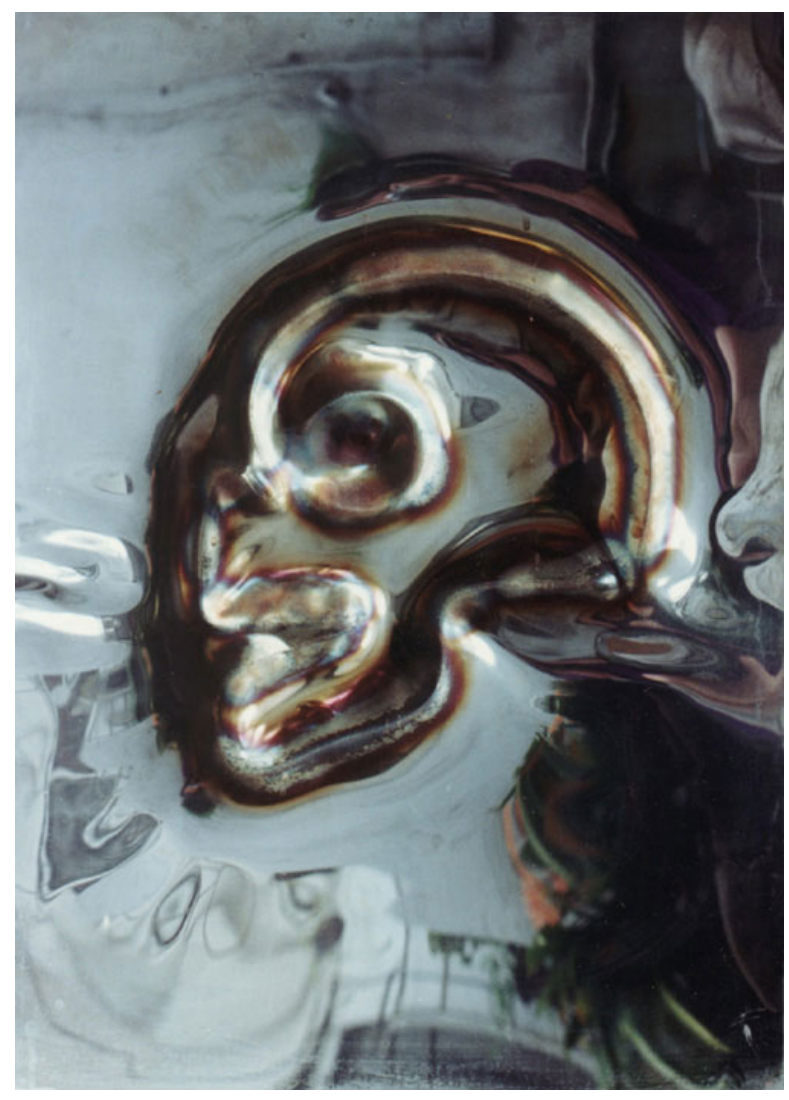

Fuente: César Martínez-Silva.

1994, con el inicio del zapatismo, se le negó el permiso, por lo que se vio obligado a trabajarla en los Estados Unidos.

El autor hace el siguiente relato para explicar el uso de explosivos para la creación de las obras de la serie Explosiciones:

Las detonaciones fueron realizadas en los bosques de Northwood, New 


\section{Artículos}

\section{Figura 6}

Serie Explosiciones. "Ritual y modernidad" (s.f.). Dinamita y nitroglicerina sobre acero inoxidable, $100 \times 70 \mathrm{~cm}$

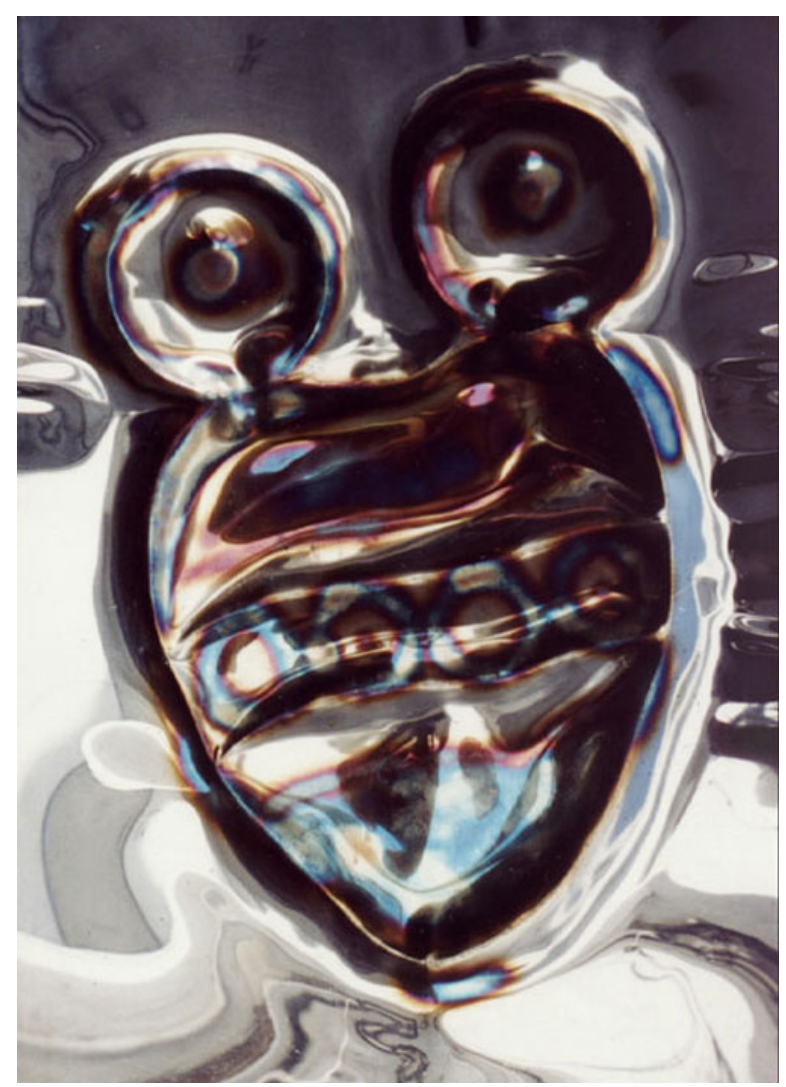

Fuente: César Martínez-Silva.

Hampshire, en los E.U.A. entre 1991 y 1993. Se utilizó para crear los bajo relieves el "cordón detonante" conocido comercialmente como "Primacord" y "Blasting caps" para su activación, cuyo contenido está hecho de nitroglicerina, misma que se activa con descargas de 11 volts. Los explosivos que se utilizaron

\section{Figura 7}

Serie Explosiciones. “Co-Razón Explosivo” (1989). Dinamita y nitroglicerina sobre acero inoxidable, $70 \times 56 \mathrm{~cm}$, Northwood, New Hampshire, USA.

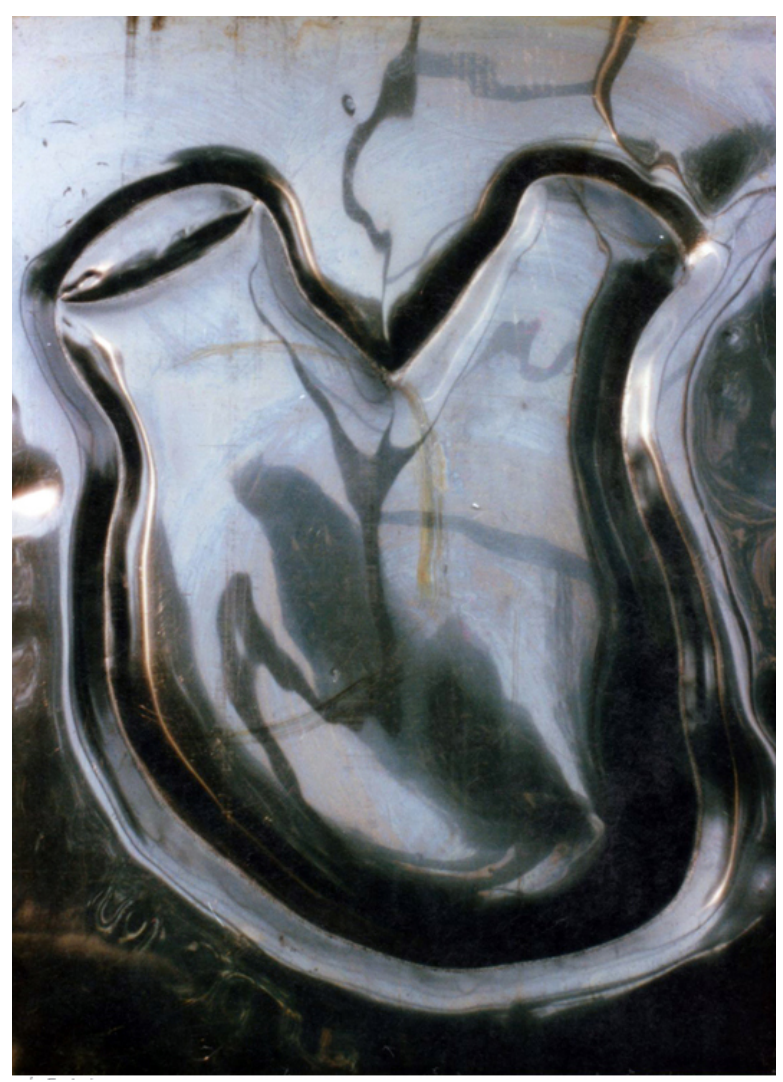

Fuente: César Martínez-Silva.

están destinados para la construcción de carreteras, perforación de minas, extinción de incendios, demolición de edificios, efectos especiales en cine, o bien, para activar a otros explosivos más potentes como son los hidrogeles. Todas las esculturas [se refiere a esa serie] fueron realizadas bajo la asesoría de la artista 
italiana Silvana Cenci, conocida como "Dinamita Lady", en los Estados Unidos de América. (Martínez-Silva, s.f.) ${ }^{10}$

Martínez heredó la técnica de Silvana Cenci, la mujer dinamita, con quien trabajó cerca de 20 años. Con ella, aprendió la fuerza paradójicamente constructora del fuego, realizando varios trabajos en co-producción. Con el arte incendiario, César Martínez-Silva se desliza de la contemplación a la conmoción estética, entendida esta como la generación de un despertar y un sacudimiento propios del arte de acción. Se suma, con ello, a la emergencia de una nueva forma de experiencia estética, alejada de la mirada extática que se conoce ante las grandes obras de arte clásico, que, aunque brindan una experiencia estética profunda e indispensable, pueden responder muy poco a los cambios políticos y sociales, y los traumas de la vida actual (Brenson citado en Danto, 2004, p. 208). En este sentido, el arte de Martínez-Silva, al generar una experiencia estética de sacudimiento, se pone frente al tipo de arte que, "[...] al ser privados sus diálogos, tienen poco potencial para hablarle a los ciudadanos de hoy" (Danto, 2004).

El arte explosivo es para César Martínez-Silva un modo de traducir estéticamente lo que percibe del entorno sociopolítico. En entrevista personal nos dice:

\section{Figura 8}

Serie Explosiciones. "La impresión del futuro" (s.f.). Dinamita y nitroglicerina sobre acero inoxidable, $90 \times 50 \mathrm{~cm}$

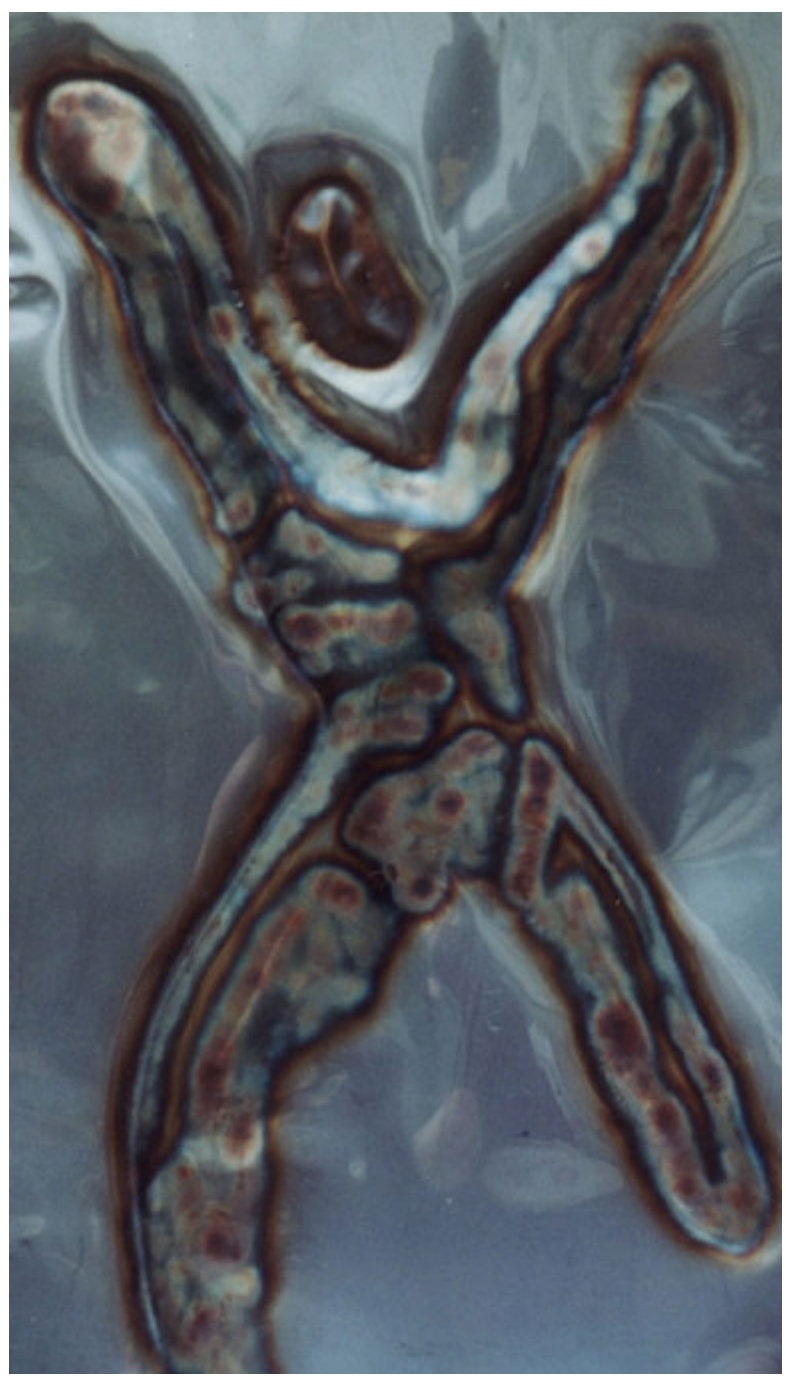

Fuente: César Martínez-Silva.

${ }^{10}$ La cita fue tomada de la autobiografía artística de la página del autor, en el que precisa que este proyecto pudo realizarse con el apoyo recibido por la beca de Jóvenes Creadores, otorgada por el Fondo Nacional para las Artes durante el año de 1991. 


\section{Artículos}

Con el arte explosivo quería decir a la gente qué tanto está explotada. Es una acción política comprometida y una visión estética que requiere de un público que aprecie la vida en otros valores fuera de lo económico y que la sobreproducción de objetos característica de la posmodernidad sea deconstruida. (M. L. González, comunicación personal, 2015)

El artista, entonces, proporciona una consolación metafísica; en palabras de Nietzsche, esto radica en una posibilidad de vivir la vida estéticamente y César Martínez-Silva lo entiende y lo practica. Así lo enuncia: "Busco crear algo que tenga alcance primeramente en mí, lo que creo me hace sentir satisfecho, me ha servido para dar sentido a la vida, y trato de generar eso mismo en la gente" (M. L. González, comunicación personal, 2015). En otro texto lo expresa de esta manera: "El arte y los artistas, podemos crear una interactividad más efectiva [...] para hacer de lo difícilmente soportable una dimensión filosófica [...] y renovemos la mirada que dirigimos al mundo más allá de lo estético" (Fundación telefónica, El final del Eclipse. El arte de Latinoamérica en la transición al siglo XXI, s.f.).

Con este tipo de obras, podríamos considerar que César Martínez-Silva se encuentra cercano a las propuestas que Danto nombra como Arte del público, un movimiento en el cual el público al que involucra la obra de arte participa en las decisiones que afectan estéticamente su vida, creando un arte no museístico; es decir, ocurre una transformación del público mismo en artista (2004, p. 208). Lo anterior, se convierte en la ambición de los artistas del performance y el propósito de Martínez-Silva: generar una participación del público yendo más allá de la contemplación en los museos, y contactando con aspectos más profundos de la persona que participa. Al respecto, Martínez-Silva se manifiesta: "[...] muy a pesar de que consideremos contradictoriamente a los museos como clínicas de salud mental, sitios neurálgicos de reflexión sensible, u hospitales de la razón, son también templos de tiempo y sitios de adoración alternativa llenos de ritos instantáneos" (M. L. González, comunicación personal, 2015). Lo que vemos hoy día -y Martínez-Silva lo muestra- es un arte que busca un contacto más inmediato con la gente de lo que permite el museo, generándose una triple transformación: en el hacer arte, en las instituciones del arte y en el público del arte (Danto, 2004, p. 210). Después del arte incendiario, este artista experimenta los "sucesos escultóricos", esculturas inflables que trabajan con el tiempo, el cuerpo y sus vicisitudes, los cuales se describen a continuación.

\section{Sucesos escultóricos}

\section{El imperdurable mente presente}

Si consideramos al arte como un proceso de vida en continuo cambio, me parecería más adecuado utilizar el término Arte extemporáneo que el de Arte contemporáneo. [...] El arte se ha vuelto un testigo del momento tris (Martínez-Silva, El final del Eclipse. El arte de Latinoamérica en la transición al siglo XXI). 
El arte efímero actual, al ser un arte del suceso que juega y trabaja con la sensibilidad de lo actual, no permanece. Este tematiza el pasar del tiempo, el desgaste y la desaparición que se va en ello, lo fugaz de la experiencia artística, incluso. César Martínez-Silva no lo elude. En El imperdurable mente presente ${ }^{11}$ el autor muestra todo un grupo de trabajos alrededor del tiempo y la ausencia que se hace presente. En dicho trabajo, lo efímero y lo fugaz, y el instante y la contingencia, son el tema central.

Como ello define también al arte actual, el autor lo expresa de la siguiente manera: "[...] el arte contemporáneo ha dejado de ser contemporáneo, ahora todo es imperdurablemente más fugaz que antes, lo ef ímero se ha vuelto más real, más sólido e inconcluso [...] lo ef ímero tiene cuerpo, ahora es más permanente que nunca". En relación con el Arte Extemporáneo, Martínez-Silva apunta que "el presente adquiere un espesor diferente, su durabilidad se vuelve más intensa a pesar de que sea más fugaz. Lo fugaz ahora es permanente" (Fundación telefónica, El final del Eclipse. El arte de Latinoamérica en la transición al siglo $X X I$, s.f.).
Y nada mejor que el cuerpo y sus vicisitudes existenciales para mostrarlo. El tema en estas esculturas también es el cuerpo, el tiempo del cuerpo, el tiempo de la vida del cuerpo y su durabilidad. El crítico y artista Blas-Galindo (1998) comenta al respecto que las representaciones volumétricas de cuerpos humanos que Martínez-Silva elabora, cuentan con rangos muy elevados de expresividad. Sentirse conmovido o agredido por su forma y desnudez, o sentir rechazo o estremecimiento, son emociones que el artista se propone provocar para estimular la sensibilidad y favorecer el desarrollo de facultades críticas y reflexivas ante las vicisitudes del ciclo de la vida y la importancia o indiferencia de los cuerpos de los otros.

En alusión al poema de Octavio Paz "Entre el irse y quedarse"12 Martínez da nombre a su grupo escultórico: El imperdurable mente presente, estableciendo como subtítulo: $L a$ asfixia o los arrebatos del pulmón politizado. En la vida, nos dirá el artista, todo está politizado, hasta el respirar.

En julio del 2002, cuando presenta esta obra, el autor escribe: "La energía necesaria para la supervivencia emana de las reacciones de la oxidación biológica [...] con conservación

\footnotetext{
${ }^{11}$ Hule látex vulcanizado, sensores de movimiento, pistola de aire y suministro. Esculturas hinchables que se inflan y desinflan cuando la presencia del espectador es detectada.

12 "Entre irse y quedarse duda el día, / enamorado de su transparencia. / La tarde circular es ya bahía: / en su quieto vaivén se mece el mundo. // Todo es visible y todo es elusivo, / todo está cerca y todo es intocable. // Los papeles, el libro, el vaso, el lápiz / reposan a la sombra de sus nombres. // Latir del tiempo que en mi sien repite / la misma terca sílaba de sangre. //La luz hace del muro indiferente / un espectral teatro de reflejos. // En el centro de un ojo me descubro; / no me mira, me miro en su mirada. // Se disipa el instante. Sin moverme, / yo me quedo y me voy: soy una pausa" (Paz, s.f.). Recuperado de http://www.poesi.as/op17019.htm
} 
Artículos

\section{Figura 9}

Serie Sucesos escultóricos. "Cuerpo-viento" (1997). Retrato en 3D del poeta y artista de performance Armando Sarignana. Homenaje escultórico que le permite "volver a respirar". Galería Marco Noire, Turín, Italia.

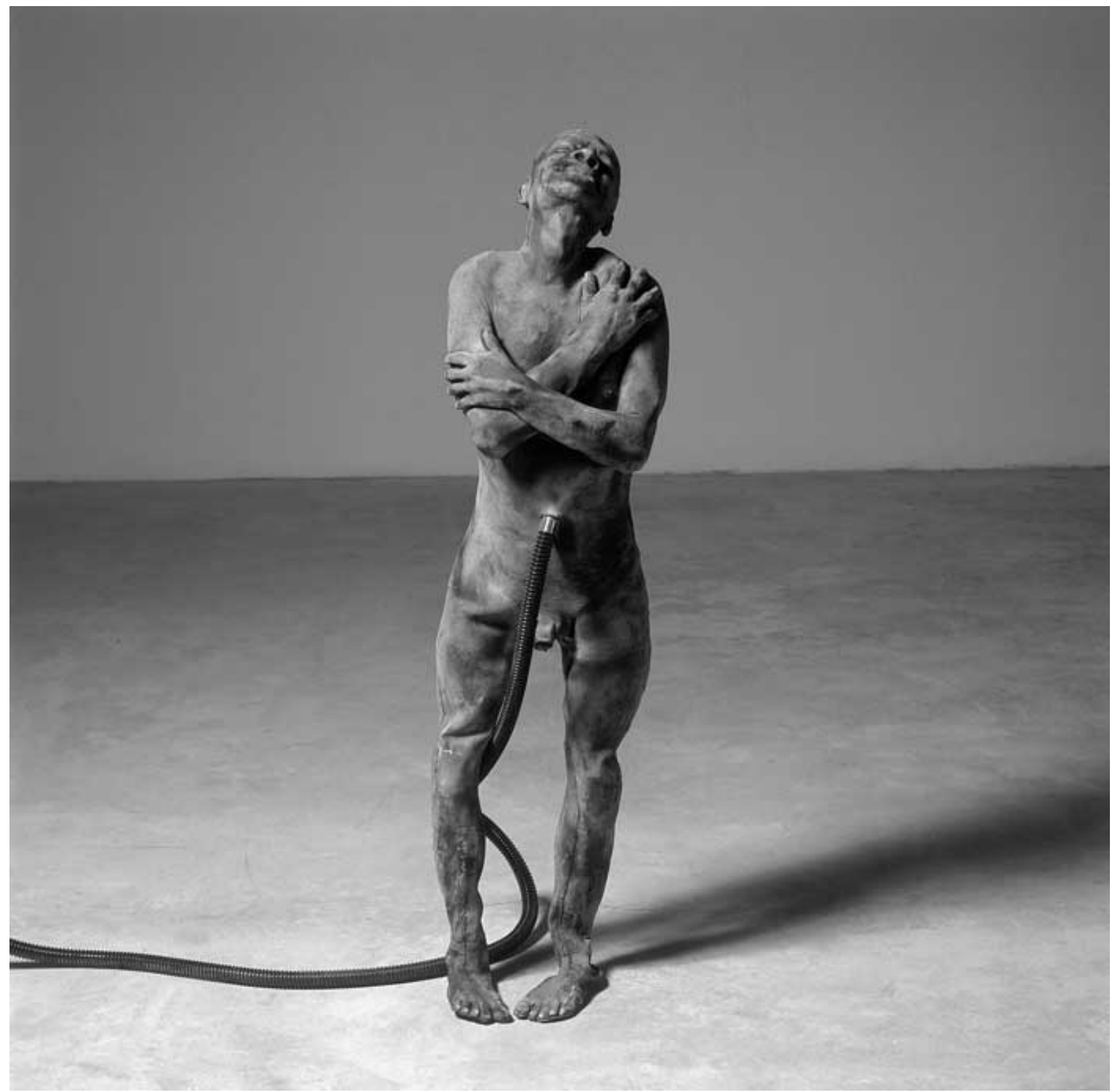

Fuente: César Martínez-Silva. 
de la energía biológicamente útil, el aire es el alma de las emociones, es el cuerpo del alma, es la naturaleza insustancial de la vida" ( $L a$ asfixia o los arrebatos del pulmón politizado, Martínez-Silva, 2002, párr.1). Así, un conjunto de 14 esculturas humanas hinchables y un "pulmón arquitectónico", compuesto con telas y aire, moviéndose al ritmo de Mozart, forman la propuesta del artista con la que prolonga su metáfora de una conciencia colectiva sobre la asfixia (Samaniego, 2014).

Del metabolismo implícito en el acto de emplear nuestras vías respiratorias a la metáfora de los ejes viales congestionados en las grandes ciudades que, de forma paradójica, impiden o dificultan en extremo tomar el oxígeno vital, Martínez-Silva extrae el concepto con el que trabaja en las esculturas inflables: "El bióxido de carbono politizado y el impuesto al oxígeno agregado -anotahan provocado que en cada momento se adormezca y se extravíe la vida al grado de confundir a las vías respiratorias en espantosos ejes viales" (Samaniego, 2014, párr. 5). Estar inflado, henchido, como metáfora de la presencia del aliento de vida, es el contraste a estar desinflado, sin ánimo, sin aliento, sin aire, sin vida. En la cotidiana contaminación "no nos damos cuenta de que el aire desaparece porque no lo vemos y, sin embargo, logramos palparlo con su ausencia, cuando nos falta" (Samaniego, 2014, párr. 5).

"Yo me quedo y me voy, soy una pausa" dice el poeta Octavio Paz. Partiendo de esto, Martínez-Silva, a través de provocar cambios de volumen con entrada y salida de aire, propone sus esculturas inflables como polarizadores del equilibrio, como un suspiro que refleja el anhelo de librarse del constreñimiento en el que el propio cuerpo nos encierra. Las esculturas inflables desafían la consistencia de una escultura: son piedra y aire a la vez; dureza y volatilidad reunidas en un cuerpo; presencia y ausencia; ser y no ser; lo anterior, muestra, según lo puntualiza el artista, la "Insoportable brevedad del ser" ${ }^{13}$. Para Martínez-Silva, además, en el acto sutil y a la vez extremadamente importante del respirar, se concentran distintos valores politizados del sentido de la vida que producen "impulsos contráctiles en nuestro oxigeno social" $y$, de ahí, los nombres de las esculturas: cuerpo-idealizado, cuerpo-respiro, cuerpo-murmullo, cuerpo-suspiro, cuerpo-eco.

Con los Artentados y los Sucesos escultóricos, se logró mostrar parte de los trabajos del artista considerados como emblemáticos y representativos de su obra, los cuales poseen marcas autorales que, de alguna manera, están en diálogo con los performances. En su biografía se encuentran documentadas ampliamente las demás producciones que, por apego a lo que se propuso en este artículo, no fueron incluidas en el presente escrito. De tal manera, se considera que en los trabajos que se presentan, aparecen implícitos los elementos que forjan las PerforMANcenas:

\footnotetext{
${ }^{13}$ En clara alusión a la novela de Milán Kundera.
} 


\section{Artículos}

\section{Figura 10}

Serie sucesos escultóricos. "El imperdurable mente presente" (2002).

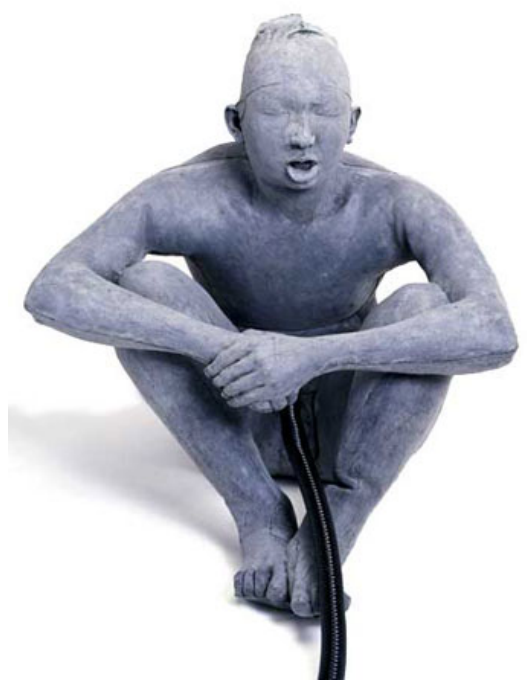

Fuente: César Martínez-Silva.

\section{Figura 12}

Serie sucesos escultóricos. "El imperdurable mente presente" (2002).

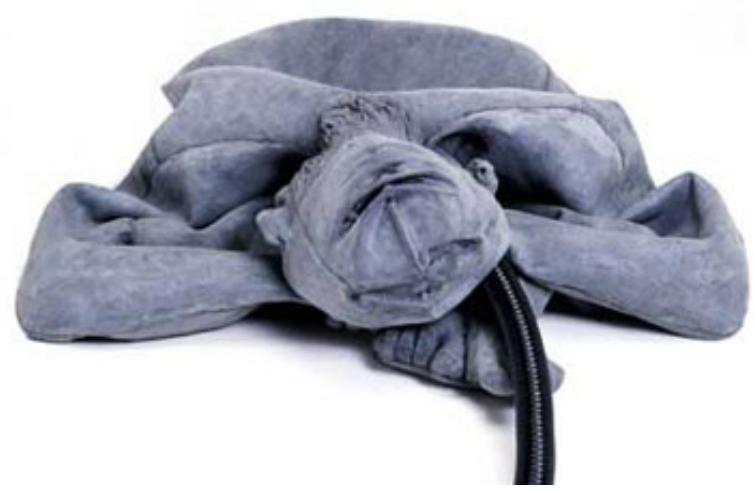

Fuente: César Martínez-Silva.

\section{Figura 11}

Serie sucesos escultóricos. "El imperdurable mente presente" (2002).

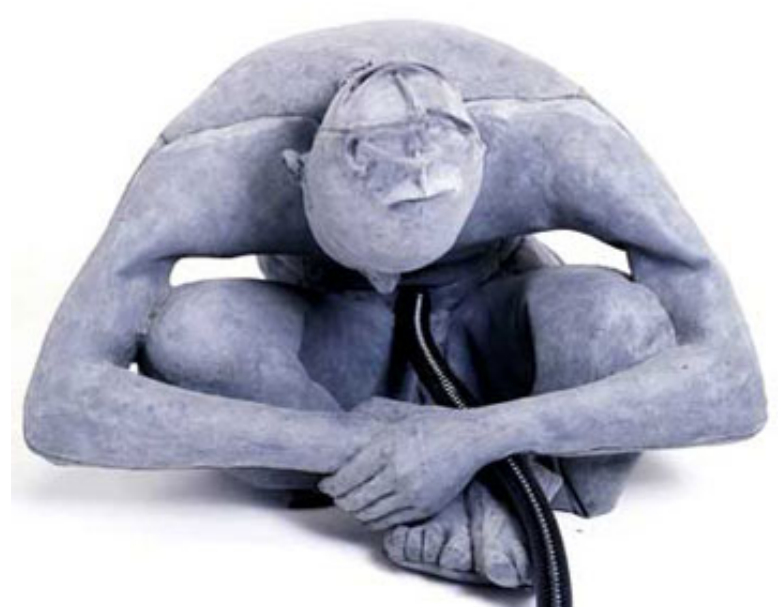

Fuente: César Martínez-Silva.

\section{Figura 13}

Serie sucesos escultóricos. "Palabras interactivas" (2002).

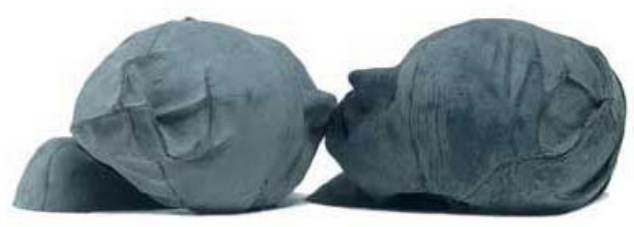

Fuente: César Martínez-Silva. 
el arte de participación del público, el tema del cuerpo, la incorporación que aquí involucra otros sentidos (la vista, el olfato, el tacto) y su compromiso social y político en la búsqueda de transformación social. En el siguiente apartado, se hará un esbozo sobre la configuración del concepto de las PerforMANcenas.

\section{Las perfor $M A N$ cenas}

Es cierto que, en diferentes rituales y sacrificios de varias culturas indígenas mexicanas, se acostumbraba comerse el corazón y partes del individuo sacrificado ofrecido a los Dioses. Comer carne humana era un rito reservado a unos cuantos, servía para fortalecerse con lo sagrado a través de (incorporar) el cuerpo sacrificado. O me atrevería a decir, cuerpo significado" (Comeos los unos a los otros, Martínez-Silva, s.f.).

Las perforMANcenas son presentaciones estructuradas como performance conceptual. El elemento central en estas es la incorporación antropofágica como estrategia estética: el canibalismo como metáfora. Basado en una amplia investigación documental iniciada con el texto de J. Acha sobre El consumo de las artes visuales y sus efectos; el conocimiento de los ritos ancestrales aztecas (sacrificios humanos); documentos históricos referidos a la donación del cuerpo propio como símbolo de redención (Xipetotec, San Bartolomeo); documentos y noticias del acontecer político de México -así como importantes experiencias personales alrededor de la incorporación simbólica del cuerpo y actos canibalísticos reales como el acontecido con el japonés Issei Sagawa- es que César Martínez articula el concepto.

Aunque estas acciones están formuladas sobre una trama similar que incluye la participación en un sacrificio y canibalismo simulado, estas obras han tenido una evolución notable desde su inicio en los años noventa, hasta la fecha, las cuales han desarrollado una trama, contexto y significado. No obstante, es importante destacar que las primeras perfor $M A N$ cenas surgen en un ambiente de corrupción y violencia ocasionado por la crisis política y social presente en México, en los años noventa (Arozqueta, 2006).

En el siguiente apartado se realizará un análisis en la configuración conceptual de dichas perfor $M A N$ cenas.

\section{Una genealogía personal}

Para Martínez-Silva, las perforMANcenas tienen su propia historia. Comienzan con sus experiencias con los rituales teosofágicos de su infancia.

En relación con esto, el artista comenta:

El ritual teosofágico de purificación católica de devorar la carne y la sangre de Cristo, me dejó muy impresionado y estupefacto desde muy pequeño. ¿Qué parte del cuerpo me comía? Me preguntaba desde mi interior con el deseo de esconder a mí mismo ese pensamiento 


\section{Artículos}

sacrílego. [...] Mi consuelo era pensar que su carne y sangre circulaban y no circuleaban por mi sistema circulatorio" (Comeos los unos a los otros, Martínez-Silva, s.f.)

$\mathrm{Su}$ infancia transcurrió, relata, entre costumbres y formas de nombrar las cosas que lo inquietaban y dejaban su impronta. "Comer pan de muerto" o echarse un "taco de ojo" eran acciones que le recorrían las papilas gustativas con cierta aversión, hasta que hubo de comprender que se trataba de analogías metafóricas. A los 18 años la infancia, y con ella sus creencias, quedó atrás. Entonces, la boca y su lengua fueron empleadas con singular gusto.

En el que fuera "el amor caníbal de los dulces comienzos". Nos relata: “[...] como amante he besado, saboreado, mordido, chupado y lamido cuerpos, [...] en la amordida espiritual de todos los días, en el rito de creACCION de los cuerpos, en la conjugación del uniVESO erótico de "creced y multipliCAOS" [negritas propias del texto original] (Comeos los unos a los otros, Martínez-Silva, s.f.).

\section{La primera escultura comestible}

La lectura de la novela de Jûrô Kara "La carta de Sagawa” (1983) impactó a Martínez-Silva. Dicha novela -basada en el testimonio de Issei Sagawa, estudiante japonés radicado en París, en 1981- relataba cómo Sagawa mató por amor a su novia, una joven artista holandesa, y comió parte de su
Figura 14

PerforMANcenas. “Hombre de Cacao” México (2001).

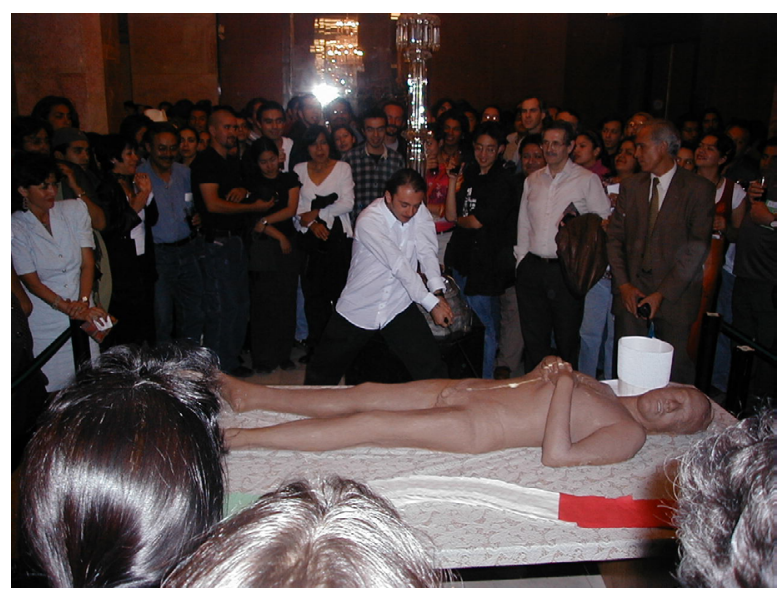

Fuente: César Martínez-Silva.

cuerpo en un rito de canibalismo moderno. Este acontecimiento, novelado por Jûrô Kara, le motivó y dio contexto a la creación de la primera performance con escultura comestible. El tema inspirador era el amor caníbal. Al respecto, anota:

El primer cuerpo humano entero comestible que realicé fue un cuerpo femenino de gelatina sabor frambuesa. Era rojo y transparente y tenía frutas tropicales en su interior simulando los órganos. Las reacciones en el Museo de Arte Moderno en México no se hicieron esperar. La mayoría de los hombres ahí presentes se tiraron el cuerpo a lamidas y mordidas libres. Fue un perfor $W O-$ MANcena. (Comeos los unos a los otros, Martínez-Silva, s.f.) 
El tema, de acuerdo con los antecedentes que hasta el momento estaban activos como experiencia en el artista, era el amor canibalístico. No obstante, las reacciones voraces del público masculino puso en alerta a Martínez -Silva sobre el uso y abuso que se ha hecho sobre la iconografía femenina en la publicidad. Así, decidió desde entonces, hacer las performances con cuerpos de hombre para contrastar las diferentes reacciones frente al cuerpo masculino en distintas circunstancias y contextos. Así se iniciaron las perforMANcenas ${ }^{14}$.

Esta serie de actos que ha repetido en diferentes partes del mundo desde entonces a la fecha, han variado de acuerdo al lugar donde se presentan y los acontecimientos políticos vigentes. Inician desde la "invit $A C C I O N$ " con el objetivo de introducir a los posibles asistentes a las dinámicas de la pieza y al contexto político en que se inscribe (Arozqueta, 2006).

\section{Los elementos conceptuales}

Siguiendo la genealogía que Martínez-Silva hace de las perforMANcenas, es posible encontrar un lugar iniciático a "El consumo artístico y sus efectos", obra de Juan Acha (1988), crítico e investigador de arte, muy apreciado por el artista. En este sentido, la obra de Acha invita a reflexionar sobre el consumo y significado de las artes visuales y sus consecuencias; sus necesidades estéticas, la psicología del consumo y sus efectos.

Permite trabajar con [...] la transformación que realiza el aparato Difestivo sobre un concepto digerido de lo que uno puede pensar y/o hacer de una obra plástica. Digerir literalmente una obra, hacerla suya, degustarla y saborearla para que luego circule como glucosa en el interior de nosotros mismos. (Martínez-Silva, 1999, párr. 5)

Como antecedentes reconocidos, Martínez-Silva incluye a Giusppe Archiboldo (1530-1593), con sus cuadros, cuyo tema central es la comida; asimismo, el autor toma en cuenta a Goya con su Saturno devorando a un hijo (1819), así como El Juicio Final de El Bosco (1482), en el que se aprecian diferentes escenas de antropofagia o canibalismo. Los panes de muerto y las calaveras de azúcar, que forman parte de la cultura popular mexicana, son también elementos inspiradores de las perforMANcenas.

Desde otra vertiente, Apollinaire, El Marqués de Sade y George Bataille han sido también sus referentes. Estos autores le han permitido a Martínez-Silva considerar que nos habita un impulso caníbal inconsciente, que, al participar en las perforMANcenas, despierta ${ }^{15}$ :

\footnotetext{
${ }^{14}$ El nombre de estas acciones juega con las palabras performance, cena, y MAN (que en inglés significa hombre), dando lugar a la idea de que en esta acción se lleva a cabo una cena donde el objeto a consumir es un hombre.

${ }^{15}$ Esta idea es desarrollada en un trabajo posterior: César Martínez, un antropófago moderno. En preparación para publicación.
} 


\section{Artículos}

Poco a poco esta información rediseñaba el concepto y el planteamiento de las perforMANcenas conduciéndome a un parámetro insólito de la incertidumbre del inconsciente caníbal colectivo. Estos autores se refieren en algunos de sus textos, a lo eróticamente apetitoso del cuerpo humano. (Comeos los unos a los otros, Martínez-Silva, s.f., párr. 4)

Un elemento central que significó un cambio conceptual en las perfor $M A N$ cenas en 1992, fue el encuentro con las series de placas de cobre que ilustran el canibalismo en la América imaginada, Americae Tertia Pars (1592) de Theodor de Bry, los cuales trasmiten la visión europeizada de la otredad como un caníbal salvaje. Este elemento, combinado con el salvajismo posmoderno en el que devorarse unos a otros se ha venido instalando como resultado de las tecnorelaciones globalizantes, devenidas del Tratado de Libre Comercio, constituyó el giro conceptual más importante.

Desde de 1991 hasta el 12 de agosto de 1992 se realizaron las negociaciones del Tratado de Libre Comercio (TLC) entre México, Canadá y Estados Unidos. Este evento se presentó como un proyecto neoliberal que pretende un continente unificado por un libre tránsito económico. Desde cierta perspectiva, esto constituyó una de las estrategias del Gobierno Mexicano para modernizar el aparato productivo, elevar su competitividad y alcanzar niveles superiores de desarrollo y bienestar (Comeos los unos a los otros, Martínez-Silva, s.f.).
Lo anterior llevó a Martínez-Silva a concebir el Tratado de libre comerse, como uno de los ingredientes conceptuales centrales de las perforMANcenas.

Con los tratados de libre comercio se descuida la ecología, los derechos humanos y laborales, la cultura y la educación. Economía significa pues, omitir, desaparecer, ignorar, chingar: es la amnesia histórica de la modernidad de los "Tratados Internacionales de Libre Comerse", [...] grave amnesia histórica de la posmodernidad, canibalismo avasallador que devora la memoria y el derecho de cada pueblo a imaginar y diseñar su propio futuro. (Comeos los unos a los otros, Martínez-Silva, s.f., párr.2)

Martínez-Silva considera que esta realidad política de México revela lo que parece increíble en pleno siglo XXI: la existencia de un canibalismo actualizado, resurgido como una práctica que aún prevalece, visualizado a través de la nueva Ley de Desestabilidad Económica, la cual resulta en un problema gastroeconómico que devora la memoria y la antigüedad de la tradición y cultura de los pueblos; este elemento es digerido en las perforMANcenas.

A continuación, se presentan algunas de las perforMANcenas que el artista ha presentado, de forma más frecuente, en diversos foros.

\section{La perfor $W O M A N c e n a$}

Esta fue la primera en presentarse. Aconteció en el Museo de Arte Moderno de la 
Ciudad de México, dentro del evento "Encuentro de primavera", organizado por la revista Generación en marzo de 1993. El tema era el consumo de cuerpos a través del erotismo. Después de observar la reacción de voracidad del público masculino, el artista decidió cambiar el cuerpo a uno masculino y medir con ello los contrastes y diferencias en las reacciones según los contextos y circunstancias ${ }^{16}$.

\section{JONHY IDEA. The last illegal alien}

Presentado en el marco del Intercambio Bi-Nacional entre artistas latinos y mexicanos. Se presentó alternativamente en la Universidad de California en los Ángeles y en el Ex Teresa Arte Actual en México DF. El cadáver a devorar era el de Johny Idea, "el último indocumentado", "el cada-ver exquisito de todos los mexicanos, the last illegal alien".

Tanto en la documentación como en relato por parte del artista, se registraron varias reacciones contrastantes. El público angelino mostró grandes reservas: solo algunos pocos se animaron a experimentar la sensación de cortar y mutilar un cuerpo, trozándolo a la mitad y en pequeñas partes. Como la gelatina era de frambuesa, el tono rojo hizo parecer como si se tratase de una carnicería. "En México, D.F. -en cambio- el público aplaudió el discurso politizado de presentación del cuerpo, para después elegir un pedazo y poco a poco hacerlo desaparecer" (Comeos los unos a los otros, Martínez-Silva, s.f., párr.2).

En esta ocasión, el cuerpo, transparente era sabor anís. Al ser colocado en una mesa de luz, se dramatizó mucho el efecto del cadáver platillo. "A pesar del error de haber utilizado más grenetina en el cuerpo, que lo hizo más duro, el público insistió en llevarse un pedacito de recuerdo" (Comeos los unos a los otros, Martínez-Silva, s.f., párr.2).

\section{The cadaver of the last immigrant}

En el evento THE TEMPLE OF CONFESSIONS, performance en colaboración con Guillermo Gomez-Peña, realizado en el Corcoran Gallery of Art en Washington DC, el público fue discreto, relata Martínez-Silva, "hasta que una puertorriqueña se comió a mordidas el falo de la escultura comestible" ${ }^{\prime 17}$.

Esta perforMANcena se replicó en el Instituto de Arte Contemporáneo de Londres, en noviembre de 1996. La reacción del público fue desbordada: descuartizaron el cuerpo, lo rebanaron, degollaron, y sus miembros terminaron regados por todo el escenario. Curioso, relata el artista, "en contraste con el anterior, este cuerpo humano masculino fue 'castrado' por un hombre muy elegante".

\footnotetext{
${ }^{16}$ No se encuentra más documentación acerca de esta primera presentación.

${ }^{17}$ No existe documentación disponible de esta PerforMANcena.
} 


\section{NORTH AMERICA Free Tanga Puesto Trade Agreement}

En el marco del 7th Annual Cherry Creeks Arts Festival en Denver, Colorado, Martínez-Silva colocó un puesto de comida humana en plena acera pública. El cuerpo, connotado como The illegal alien, fue devorado completamente.

\section{North America Cholesterol Free Trade Agreement}

Esta práctica artística fue realizada en el Museo de Arte Contemporáneo Carrillo Gil, en el marco del evento Las transgresiones al cuerpo. La reacción del público, después de escuchar el discurso político- religioso, consistió en besar y cortar al cuerpo en pedacitos y llevarse un "itacate".

Aquí el relato documentado de esta perforMANcena:

El ritual fue conducido por un carnicero con apariencia de Jesucristo, con pelo largo y barba, que portaba debajo de un delantal ensangrentado y una playera estampada con el sagrado corazón. El artista inició la acción subiendo las escaleras del edificio acompañado de campanas y música religiosa, sacó de una bolsa de plástico estampada con la bandera de Cánada dos cuchillos y los enterró en el estrado. La acción simulaba una misa católica dictada en nombre de México, Cánada y los Estados Unidos. En ella se proclamaba la grandeza del dólar y del Tratado de Libre Comercio, la sumisión de los fieles mexicanos ante sus gobiernantes y las políticas de consumo que favorecen a Norteamérica. (Arozqueta, 2006)

El discurso rezaba como sigue:

\section{De Pie)}

En el nombre de México, Canadá y los Estados Unidos...

\section{Viva el TLC}

El TLC, que viene a salvarnos, esté con todos Ustedes.

Proclamemos la grandeza del dólar, se alegra mi espíritu con este gran señor de todas las cosas, nuestro salvador, porque ha mirado con humillación a los esclavos de la economía redentora (...)

\section{SENTADOS}

ASÍ, aquí yace el cuerpo de Johny Idea, de América Gelatina, exhibicionismo a la postre en este North America Fat Free Trade Agreement, very wild consumerism, costumed consumerismo (...)

\section{CREDO}

Creo en la medida de todas las cosas, de todo lo visible y lo invisible, creo en el Tratado de Libre Comer-se, the only option, nacido de toda la corrupción de todos los siglos y centuries. ${ }^{18}$

\footnotetext{
${ }^{18}$ Tomado del archivo del artista en la dirección http://martinezsilva.com/index.php?/performancenas/ north-america-cholesterol-free-trade-agreement/
} 


\section{Figura 15}

Serie North America Free Tanga puesto over America Ge-Latina. (1997). Denver, Colorado, USA. Curaduría de Guillermo Gómez Peña y Lorena Wolffer.

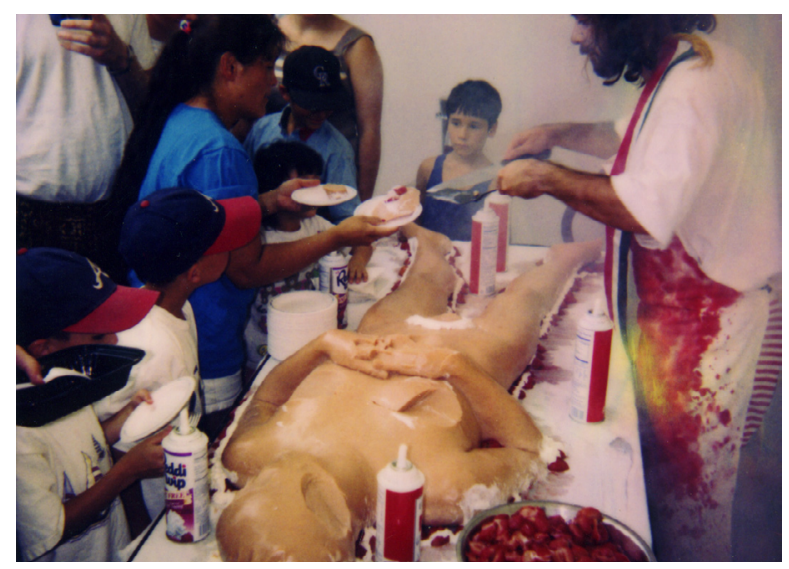

Fuente: César Martínez-Silva.

Una vez terminado el discurso y después de un réquiem militar, el artista decoró la gelatina con más crema chantilly e invitó a los asistentes a cenar y a que se sirvieran la parte que desearan (Arozqueta, 2006).

\section{Ame Rica G-Latina}

En 1999, en la Casa de América en Madrid, para la exhibición $A$ vuelta con los sentidos, Martínez-Silva llevó a cabo la perfor $M A N c e-$ na "Ame Rica G-Latina”. El discurso presentado aprovechó las relaciones históricas entre México y España. El tema era el mestizaje, la América imaginaria en la visión europea y la situación política mexicana, en alusión al EZLN (Ejército Zapatista de Liberación $\mathrm{Na-}$ cional). Para transmitir su mensaje, apareció

\section{Figura 16}

Serie North America Cholesterol Free Trade Agreement. (1997). Museo de Arte Carrillo Gil. Dentro de la muestra Transgresiones al cuerpo, Curaduría de Edgardo Ganado Kim.

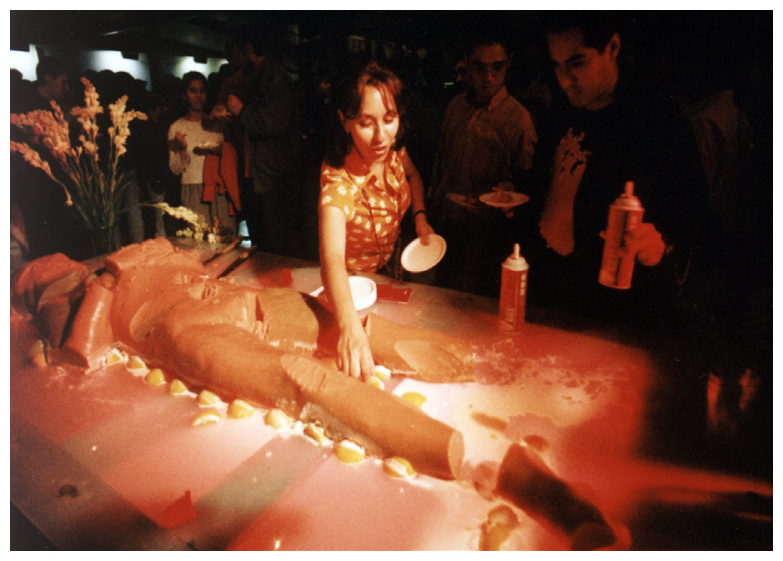

Fuente: César Martínez-Silva.

en escena, un hombre desnudo, con un pasa montañas y con un cuchillo de carnicero. Frente a su gelatina "escultococinada" que representaba a un indígena contemporáneo declara:

Yo América

Yo Amé rica

Yo Ame Rica Latina

Yo América G-Latina

Fantasía Europea

Fantasía Mestiza

Incógnita facial

Geografía del cuerpo

Norte SUR Este $\boldsymbol{O}$ éste

Territorio imaginario

Frontera de los sentidos

Mestizaje emocional.

Memoria digestiva 


\section{Artículos}

Amnesia Histórica

Amnesia Histérica

Amnecios $^{19}$

Al finalizar su discurso, Martínez-Silva procedió a extraer el corazón de melón esculpido, comiendo una parte de él y ofreciendo luego a los concurrentes, en una mezcla alusiva a los sacrificios prehispánicos y a la comunión cristiana. Martínez-Silva relata que al llegar al lugar de la presentación, no preveía que este sería el Cuartel General del Ejército Español, mucho menos que estaría bajo la supervisión del Coronel Villarejo y que contaría con la generosa ayuda de varios militares para escultucocinar el cuerpo de gelatina. Así que "esto significó que durante la perforMANcena, el español se comió al indio, el primer mundo se comió al tercero y la amnesia histórica se devoró a la amnesia social, a un concepto internacional: ChiaPAZ, voz que haba por muchos mexicanos" (Martínez-Silva, s.f.).

Esta perforMANcena constituyó un viraje en el concepto de las anteriores. Se replicó en otras presentaciones en otros países y espacios artísticos. Su estructura, textos e ingredientes variaron según el contexto. Algunas fueron de chocolate e ingredientes de la región. Actualmente, Martínez-Silva ha desarrollado la perforMANcena denominada "Xipetotec" actualizando el rito azteca del desollado: aquel que "se quitó la piel para alimentar al mundo, promover la riqueza, la abundancia y el amor". Este performance,
Figura 17

Serie Ame-Rica G-Latina. "Se extrae el corazón de melón". (1999)

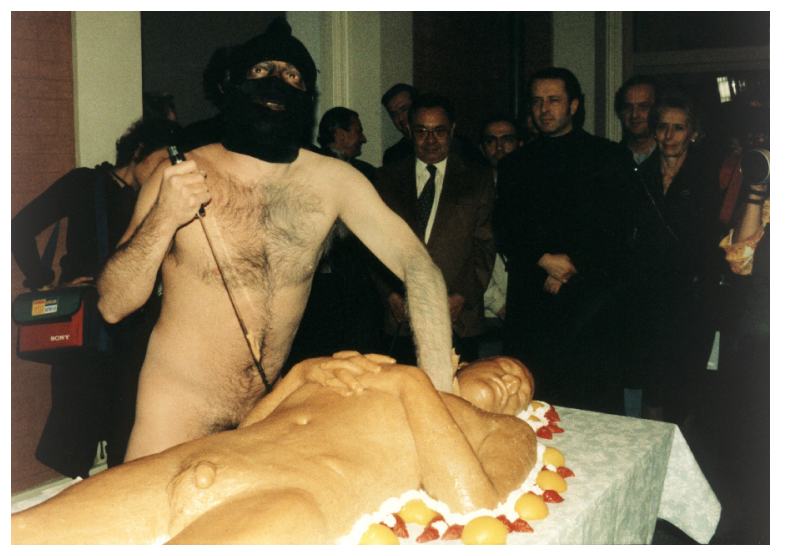

Fuente: César Martínez-Silva.

está inspirado por el mismo propósito que sus anteriores producciones: "el arte debe nutrir" (Martínez-Silva, s.f.).

\section{Conclusiones}

Antes de esbozar algunas conclusiones, es necesario realizar un breve recuento: en lo que antecede, se ha presentado al artista César Martínez-Silva en su genealogía y trayectoria, procurando dar lugar a su palabra en lo que atañe a su concepción del arte en general, de sí mismo como artista, y de su propia producción, particularmente en lo que se refiere a la metáfora de la incorporación en las perfor $M A N$ cenas.

\footnotetext{
${ }^{19}$ Fragmento del discurso con el que el artista inició la perforMANcena (Arozqueta, 2006).
} 
En este sentido, se muestra cómo este artista se inició en el performance en contacto con la tradición vanguardista de los Grupos y los primeros artistas de performance en México, y cómo fue concibiendo el concepto de las perforMANcenas, en una articulación de elementos de su historia personal, su filiación al arte experimental y de vanguardia, así como a la estética relacional de la década de los noventa. Asimismo, observamos cómo el artista hace un entramado entre canibalismo y acontecimiento político para articular el argumento medular de las perforMANcenas. En sus declaraciones y documentaciones de la obra, se constata, de igual manera, la expresión de sus propósitos de crear consciencia social.

A lo largo de la presente indagación de la documentación de la obra de Martínez-Silva, se logró identificar cómo en esta la incorporación en sus modalidades visual, auditiva, olfativa, táctil y principalmente oral, ha sido empleada como metáfora del consumo, apropiación, asimilación y conocimiento del sentido que esta genera o porta.

De igual manera, se mostró cómo desde sus inicios en 1993 a la fecha -aunque modificado en sus argumentos textuales para adecuarlo a los contextos y circunstancias actuales-, el concepto de la incorporación como estrategia estética permanece. Para César Martínez-Silva la incorporación en un acto colectivo puesta en acto en las perforMANcenas sigue siendo el medio para transmitir, afectar, accionar, promover la experiencia del arte.
Visto desde la óptica psicoanalítica, resulta necesario considerar que el artista antecede al psicoanalista en el saber de la condición humana. S. Freud, en sus ensayos sobre arte -entre los que destacan "Caracteres psicopáticos en el escenario" (1906); "El delirio y los sueños en la Gradiva de W. Jensen (1907) y "El creador literario y el fantaseo" (1908) - se centra en el estudio del proceso creativo y de la técnica artística en función del logro estético. Asimismo, en su trabajo titulado "El múltiple interés del psicoanálisis" (1913), este plantea que la obra de arte y su proceso de construcción se convierte en uno de los objetos más atractivos de la investigación analítica. De forma posterior, realiza lo que llamará biografías artísticas para enfatizar la importancia del estudio de la vida del autor en el conocimiento y comprensión de su obra. En este tipo de ensayos destacan "Un recuerdo infantil de Leonardo da Vinci" (1910); "El Moisés de Miguel Ángel" (1914); "Un recuerdo infantil de Goethe en Poesía y verdad (1917) y "Dostoievski y el parricidio" (1928).

Así, resulta del todo necesario puntualizar la forma en la que se articuló el ensayo en torno a César Martínez-Silva y la trayectoria de su obra, resaltando la importancia de articular una semblanza y trayectoria del artista, como lo indican el abordaje psicoanalítico de una obra artística, además del ya señalado método de A. Danto. En este caso, ya que el artista aún vive, ese propósito puede lograrse con mayor precisión y amplitud, pues se tiene su voz en vivo, aportando otra dimensión del artista, distinta de la voz escrita en 


\section{Artículos}

sus declaraciones y/o manifiestos o de lo que la obra misma puede decir aún sin la palabra del artista. Con ello se da lugar a una forma de investigar las producciones artísticas contemporáneas con artistas vivos, el cual permite producir una discursividad que muestra la relación que el artista tiene con su obra y que tiene su importancia en la comprensión de esta y en su contextualización.

Un análisis más detallado de las perfor $M A N$ cenas en cuanto a su articulación estética como la actualización performática de rituales teosofágicos y canibalísticos antiguos que el artista se apropia para generar nuevos sentidos y conciencia de época, así como la puesta en cuestión del eurocentrismo en las artes y la cultura, articula el concepto que propongo denominar para nombrar estos performances como In-corpo-r-arte ${ }^{20}$.

Aunque por definición es político y efímero, el performance, sin embargo, no es solo el acto vanguardista fugaz, sino un acto de transferencia que permite que la identidad y la memoria colectiva se transmitan a través de ceremonias compartidas o comportamientos reiterados ya que funcionan como actos vitales de transferencia, transmitiendo saber social, memoria y sentido de identidad a través de acciones reiteradas, o lo que $\mathrm{Ri}$ chard Schechner llama conducta restaurada (2011). Desde esta perspectiva, lo profundo, genuino o individual de una cultura, no sólo es revelado en los performances, sino, además, puede ser reeditado y reformulado.

En sus performances, César Martínez-Silva muestra ampliamente cómo la fuerza de innovación y convocación que tiene el arte del performance depende de la habilidad para romper barreras y para recombinar elementos e ideas dispares (Taylor, 2011, p.9). Así, los ritos teosofágicos y los rituales caníbales ancestrales son amalgamados metafóricamente para generar una forma incorporativa de metabolizar la realidad política y provocar una ampliación de la conciencia.

Lo que a mi juicio esta semblanza aporta para la comprensión de la trayectoria artística de César Martínez-Silva y el lugar que el performance tiene en la escena del arte, es la importancia de un arte integral con el que testimonia su sólida convicción de que este es el arte que viene bien a nuestra época, ya que a la vez que la ilustra, actúa como agente de cambio.

Los artistas de performance son unos convencidos de la necesidad de contacto más estrecho entre arte y vida, de hacer poderosa y persistente resistencia que contrarreste las crecientes imposiciones mercantiles sobre la obra artística. El performance, más que ninguna otra producción artística, no se deja apropiar ni fetichizar: por el contrario, este apuesta, en cambio, a la fuerza de una conmoción estética que perdure en una transformación subjetiva.

${ }^{20}$ In-corpo-r-arte, es el nombre del proyecto de investigación de la obra de César Martínez Silva. Lo presentado en este ensayo es la primera parte. Es una investigación en curso. 


\section{Referencias}

Arozqueta, C. (2015). La metáfora del canibalismo en las PerforMANcenas de César Martínez Silva.Recuperado de http:// martinezsilva.com/articulos/ClaudiaArozqueta.pdf

- (2015). La dislocación simbólica. Recuperado de http://martinezsilva. com/articulos/UMELEC.pdf.

Blas-Galindo, C. (1998). César Martínez Sil$v a$. REBELDÍA Y EXPRESIVIDAD. Recuperado de http://martinezsilva.com/ articulos/Rebeldia_Expresividad.pdf

Carretón, V. (2015). Respiracion Asistida. Recuperado de http://martinezsilva.com/ articulos/Respiracion\%20Asistida.pdf

Clausberg, K. (s.f.) "Sin aliento". Esculturas en látex de César Martínez. Recuperado de http://martinezsilva.com/articulos/ Sin_Aliento.pdf

Danto, A. C.(2009). Después del fin del Arte. El arte contemporáneo y el linde de la historia. Barcelona: Paidós estética

Díaz, L. (s.f.). César Martínez, el aliento de la vida. Recuperado de http://martinezsilva.com/articulos/AlientoVida.pdf

Ferreira de Almeida, M. C. (s.f.). Po(i)éticas antropofágicas: reflexões sobre uma perspectiva brasileira para a crítica de arte. Recuperado de http://martinezsilva.com/ articulos/Po_ticas_antropof_gicas.pdf
Freud, S. (1986). Obras Completas. Argentina: Amorrortu Editores.

González, M.L. (2013). El artista corporal como sublimador de la subjetividad posmoderna. (Tesis doctoral). México: Universidad de Guanajuato.

Jiménez, C. (s.f.). El espíritu en el ventilador. Recuperado de http://martinezsilva. com/articulos/El\%20espiritu\%20en\%20 el\%20ventilador.pdf

Jiménez, J. (s.f.). Ecoperformer. Recuperado de http://martinezsilva.com/articulos/ Ecoperformer.pdf

Kara, J.. (1983). La carta de Sagawa. Barcelona: Editorial Anagrama.

Martínez-Silva, C. (s.f.). El final del Eclipse. El arte de Latinoamérica en la transición del siglo XXI. Fundación telefónica. http://martinezsilva.com/articulos/ El\%20mar\%20esculpe.pdf

. (s.f.). El arte es de quien lo trabaja. Recuperado de http://martinezsilva. com/articulos/La\%20Obra\%20De\%20 Arte.pdf

(s.f.). Tesis de doctorado. Cuerpo, política y subjetividad. Performance $y$ prácticas antagónicas. Universidad de Castilla La Mancha, campus Cuenca, España. http://martinezsilva.com/index. php?/artista-indisci/biografia/

. (s.f.). Comeos los unos a los otros. Recuperado de http://martinezsilva.com/ 
articulos/Fisuras TextoPRINT.pdf

. (s.f.). PerforMANcena original de César Martínez http://martinezsilva.com/ articulos/AvueltaSentidosPRINT.pdf

\section{(s.f.). North America Cholesterol} Free Trade Agreement. Recuperado de http://martinezsilva.com/index.php?/ performancenas/north-america-cholesterol-free-trade-agreement/

. (s.f.). PerforMAN-cena (Performance-Meal). Publicado en Corpus Delecti Performance Art of The Americas. http://martinezsilva.com/articulos/Corpus\%20Delecti.pdf

. (s.f.). Play One: Ni la verdad os hará libres ni Dios sabe lo que hace o arte y misterio no son la misma cosa. Recuperado de http://martinezsilva.com/articulos/El\%20mar\%20esculpe.pdf .

- (s.f.). Canibalismo. Recuperado de http://martinezsilva.com/articulos/Canibalismo_origen.pdf

. (2002). El imperdurable mente presente. La asfixia o el pulmón politizado. http://martinezsilva.com/articulos/Imperdurablemente1.pdf

. (2002). PerforMANcena. A vuelta con los Sentidos. Recuperado de http:// martinezsilva.com/articulos/AvueltaSentidosPRINT.pdf

Montiel, J. A. (2004). Envolturas (para curar) del tedio. El arte neumático de
César Martínez Silva. http://martinezsilva.com/articulos/Envolturas_curar el\%20tedio.pdf

Pérez-Reverte, A. (s.f.). Pajínas Kulturales. Recuperado de http://martinezsilva. com/articulos

Ramírez, J. (s.f.). Hombre-Performance. http://martinezsilva.com/articulos/JosueRamirez.pdf

Samaniego, F. (2004). El arte neumático de César Martínez. El País. Recuperado de http://martinezsilva.com/articulos/ El\%20arte\%20neumatico.pdf

Santana, A. (s.f.). Del antropólogo indiscreto, el tequila y la orgía. Recuperado de http://martinezsilva.com/articulos/ Del\%20antropologo\%20indiscreto.pdf (2006). El reverso de la escritura. Recuperado de http://martinezsilva. com/articulos/cesar_venexilco.pdf

Schechner, R. (2011). La conducta restaurada. En Taylor, D. y Fuentes, M. (Comp.), Estudios Avanzados de Performance (pp. 31-50). México D.F.: Fondo de Cultura Económica.

Taylor, D. y Fuentes, M. (Comp.). (2011). Estudios Avanzados de Performance. México D.F.: Fondo de Cultura Económica.

Vattimo, G. (2007). El fin de la modernidad. Nihilismo y hermenéutica en la cultura posmoderna. Barcelona: Gedisa. 


\section{Artículos}

59 ESCENA. Revista de las artes, 2016, Volumen 76, Número 1, págs. 27-58 ISSN 1409-2522 